\title{
越冬中に頭羽の伸びたオオハクチョウ
}

\author{
柿 澤 亮 三*
}

新潟県北浦原郡水原町にある漂湖は，才オ八クチョウ(Cygnus c. cygnus) の渡来地として 知られている。筆者は数年来, 㼼湖に渡来, 越冬するオオ八クチョウの生態を研究している。 1976〜77年の冬のシーズンに，1 羽のオオ八クチョウの雌・成鳥の頭羽がだんだん伸びてくる という興味深い事例を観察したので報告する。

この異常個体を最初に観察したのは，1976年12月29日〜1977年 1 月 2 日の調査時であった。 12月18日に観察したときには気づかなかったので，このときには頭羽にほとんど異常が見られ なかっためか，あるいはたぶん，12月下旬以後に渡来した束のと考えられる。初めて観察した ときは，頭羽がボサボサと乱れた個体が 1 羽いるなと感じるぐらいで，さして気にとめなかっ た。

15日後の調査で再びその個体を観察した。前回見たとき頭羽の乱れだと思っていだのが， 一層盛り上って見えたので写真にとり，少し詳しく観察した結果，羽毛が伸びだしていたこと を発見した (Plate 14a，1977年1月17日)。それ以後の頭羽の伸びていく経過を，Plate 14b, 1 月30日：Plate 15a，2月17日：Plate 13，15b，3 月12日：Plate 16a，3月21日，に示した。 これらの写真により，このオオ八クチョウの頭羽が異常に伸びていっていることがわかる。こ の成鳥はつれあいの成鳥と， 2 羽の幼鳥との 4 羽の家族として生活していた (Plate 16b) 〔成 鳥の pair の雌雄の決定についてはここでは述べないが，柿澤（1976）に述べられているょう に，家族行動の観察により雌雄の決定を行なった」。

オオ八クチョウの頭部は, ふつう $2 \mathrm{~cm}$ から $3 \mathrm{~cm}$ の短か心羽毛で密にうめられている。しか し，この個体の異常に伸びた羽毛は，正羽と呼ばれているオオ八クチョウの体をおおっている 長さ $10 \mathrm{~cm}$ ほどの体羽と同じもののように観察された。

今回みられたようなオオ八クチョウの頭部に異質の羽毛が生えた例は，他にまだみつかって いない。他の野鳥に打ける例も筆者は知らない。このような羽毛の生成の原因は不明である。 先天的な突然変異かもしれないし, 頭部の怪我などが原因で, 後天的にその部分の組織が変化 したという可能性り考えられる。

家禽のなかには人為洦汰の結果による变異個体が多い。Grzimek (1972)の「動物百科」第 8 巻には, カワラバト，ニワトリに“かんむり”のある数品種が図示されている。ガンカモ科 の家禽にも“かんむり”のある数品種が知られている。黒四（1939）の「雁と鴨」にはカンム リアヒル，カンムリコアヒル，バリーダックというやはり“かんむり”をもったアヒルの品種 が記載されている。Delacour (1973) の「世界のガンカモ」第 4 巻には，カンムリガチョウが 記載されている。家禽でたびたびみられるこの変異は, 鳥類のもつ潜在的な変異形質の一つで あろう。今回の例に見られるように，野外の鳥類に打いてもその変異の出現の可能性が充分考

* 山階鳥類研究所 東京都渋卻区南平台町 8-20 (₹150) 
えられる。

文献

Delacour, J. 1973. Domestic Waterfowl. In The Waterfowl of the World. Vol. 4: 154-166. Country Life, London.

Grzimek, B. (ed.) 1972. Grzimek's Animal Life Encyclopedia. vol. 8, Birds II. New York.

柿澤亮三・柿澤佳子 1976. 再渡来した漂湖のオオ八クチョウ。階鳥研報 8(3)：Plate 17-18, 270-275.

黑田長軆 1939. 隻と鴨。修教社書院，東京，

\section{A female "Crested" Whooper Swan Cygnus c.cygnus wintering at Hyoko in Nigata, 1976-77 winter}

\section{Ryozo Kakizawa}

A particular female Whooper Swan Cygnus c. cygnus, wintering at the well known swan and other waterfowls resort, lake Hyoko, was kept under observation in 1976-77 winter. Here the swans and waterfowls are well tamed by artificial feeding. This particular female arrived at Hyoko in late December with her mate and 2 cygnets. In my first observation in December, her crown seemed to be somewhat unkempt, but it was not so curious.

As the time went by her crown feathers became longer. This changing process is shown by Plates $13-16$.

Yamashina Institute for Ornithology, 8-20 Nanpeidai-machi, Shibuya-ku, Tokyo 150, Japan. 


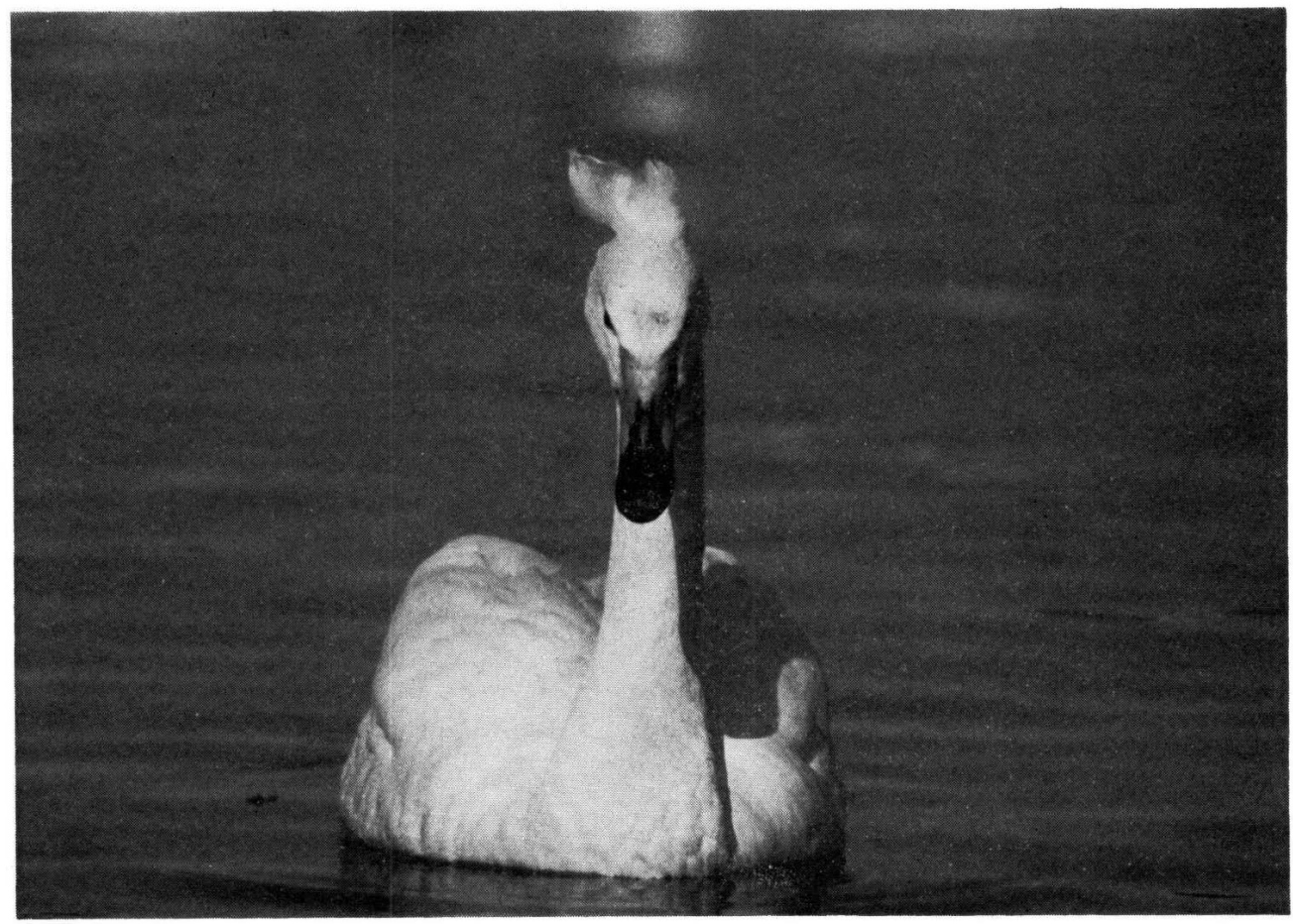

Plate 13. 頭羽が伸びて“かんむり”となったオオハクチョウ・䧳・成鳥（1977年3月12日撮影） A female "Crested" Whooper Swan Gygnus c. cygnus. (March 12, 1977)

Plate 14. a. 1977年 1 月17日撮影 (January 17, 1977)

b. シイナを採食する。1977年1月 30 日撮影, Feeding on Siina, unripe rice (January 30, 1977)

Plate 15. a. 1977年 2 月17日撮影 (February 17，1977)

b. 1977 年 3 月 12 日撮影 (March 12，1977)

Plate 16. a. シイナを採食する。1977年 3 月21日 撮影

Surface feeding on siina, unripe rice (March 21, 1977)

b. “かんむり”才オ八クチョウの家族〔成鳥の pair と 2 羽の幼鳥 (J)]，幼鳥は 正常な頭羽をしている。1977 年 3 月 21 日撮影.

She formed a family with her mate and 2 cygnets ( $\mathrm{J}$ : Juvenile), Two cygnets seemed to be normal crown. (March 21, 1977) 


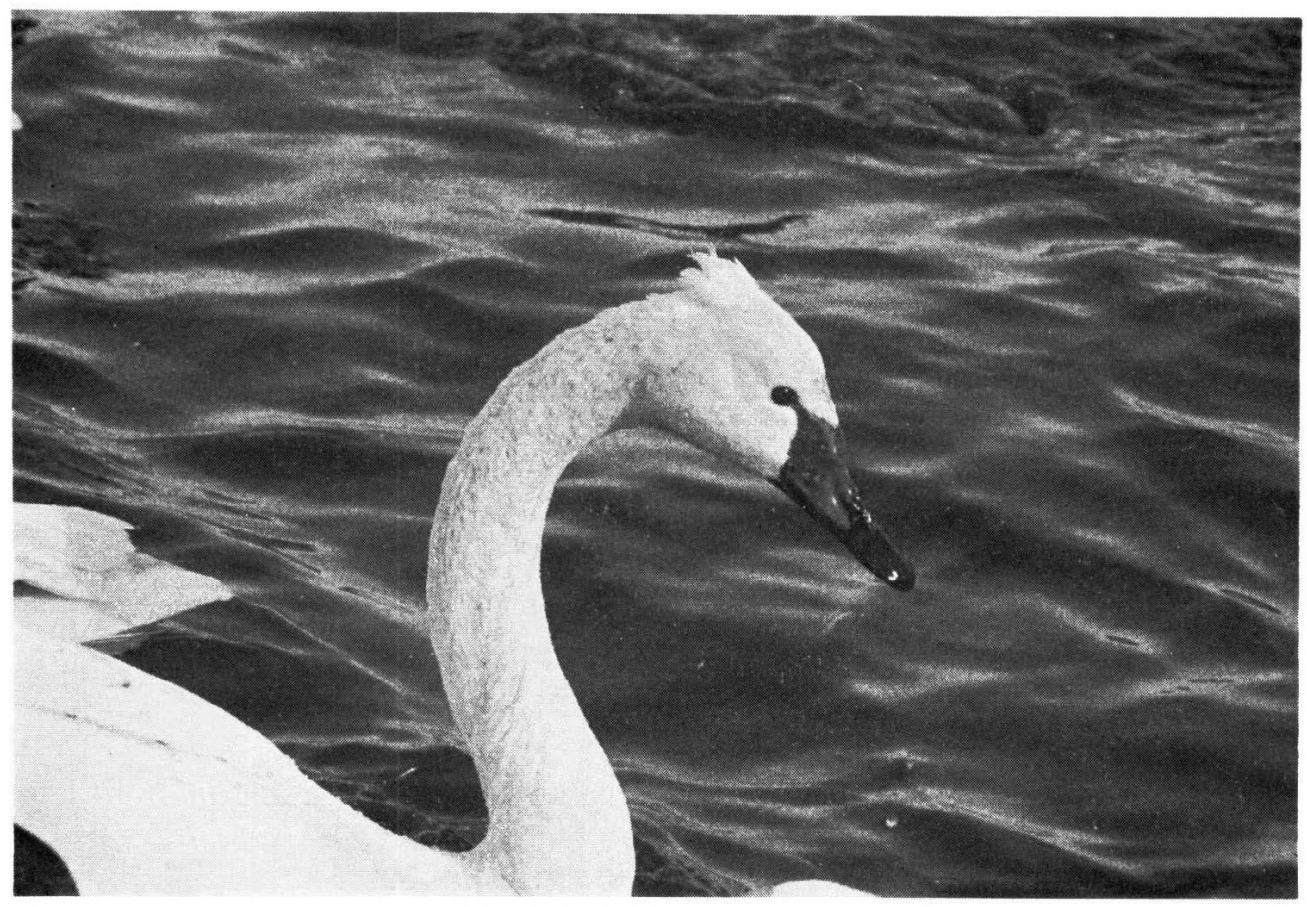

$a$

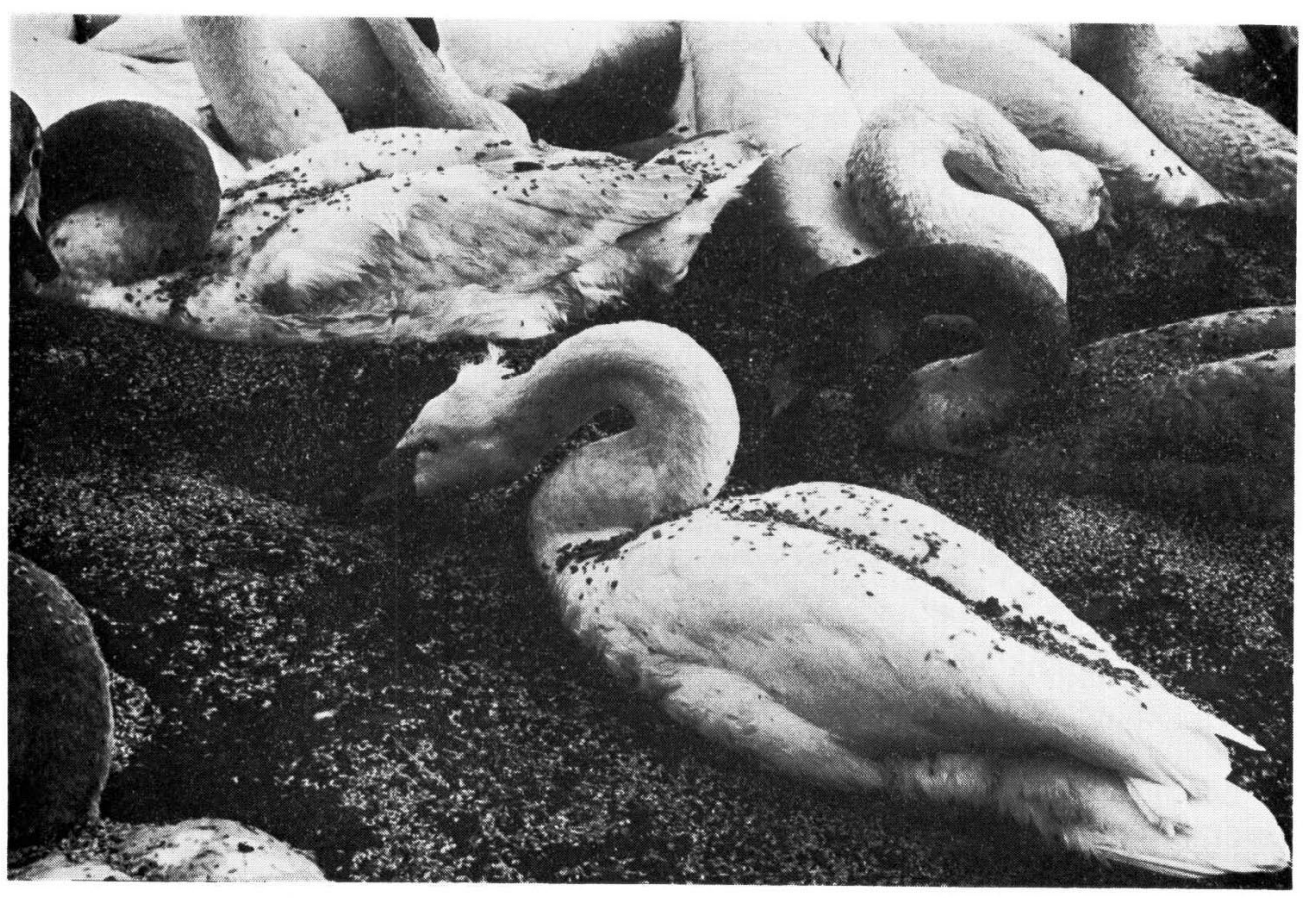

$b$ 


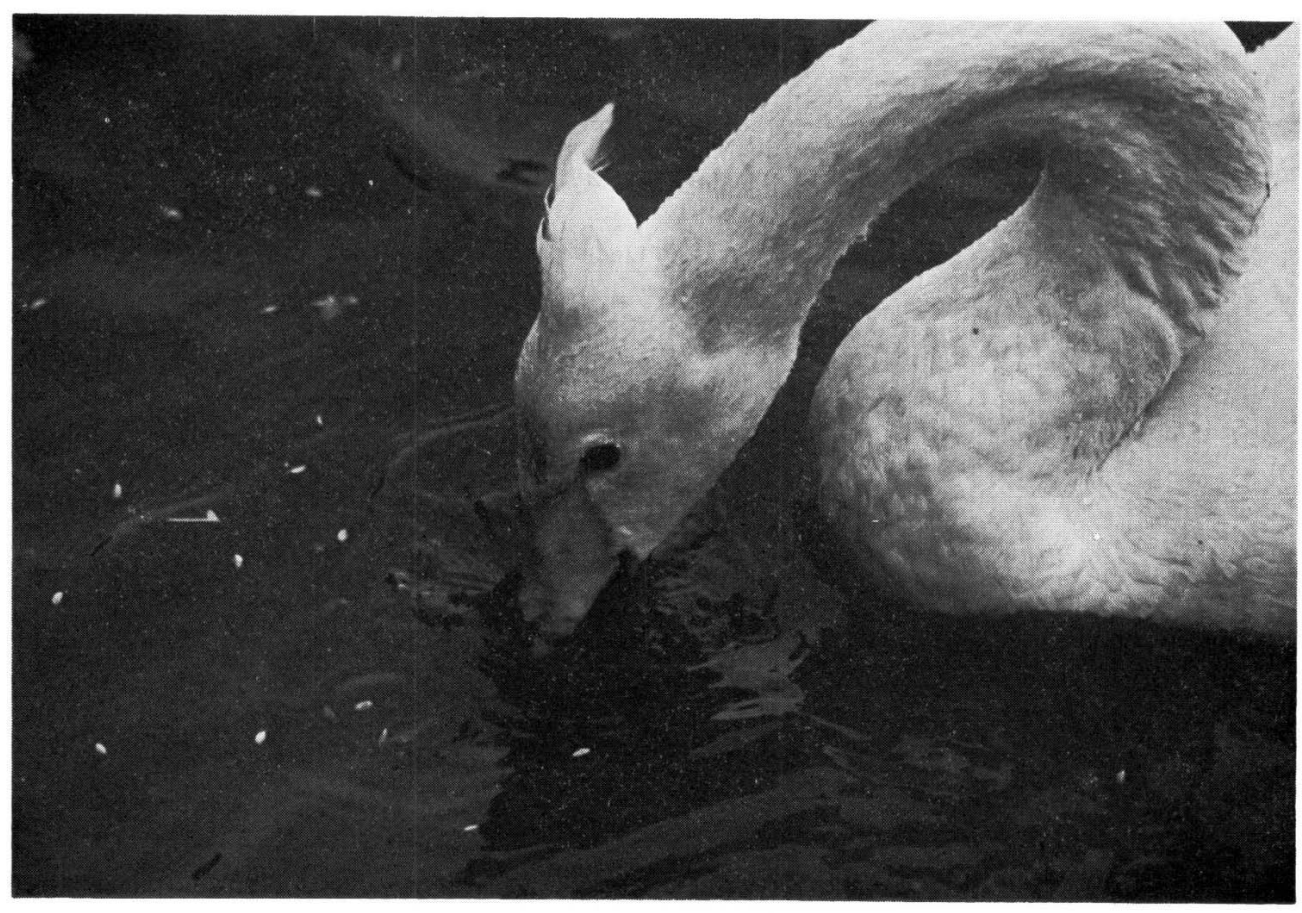

$a$

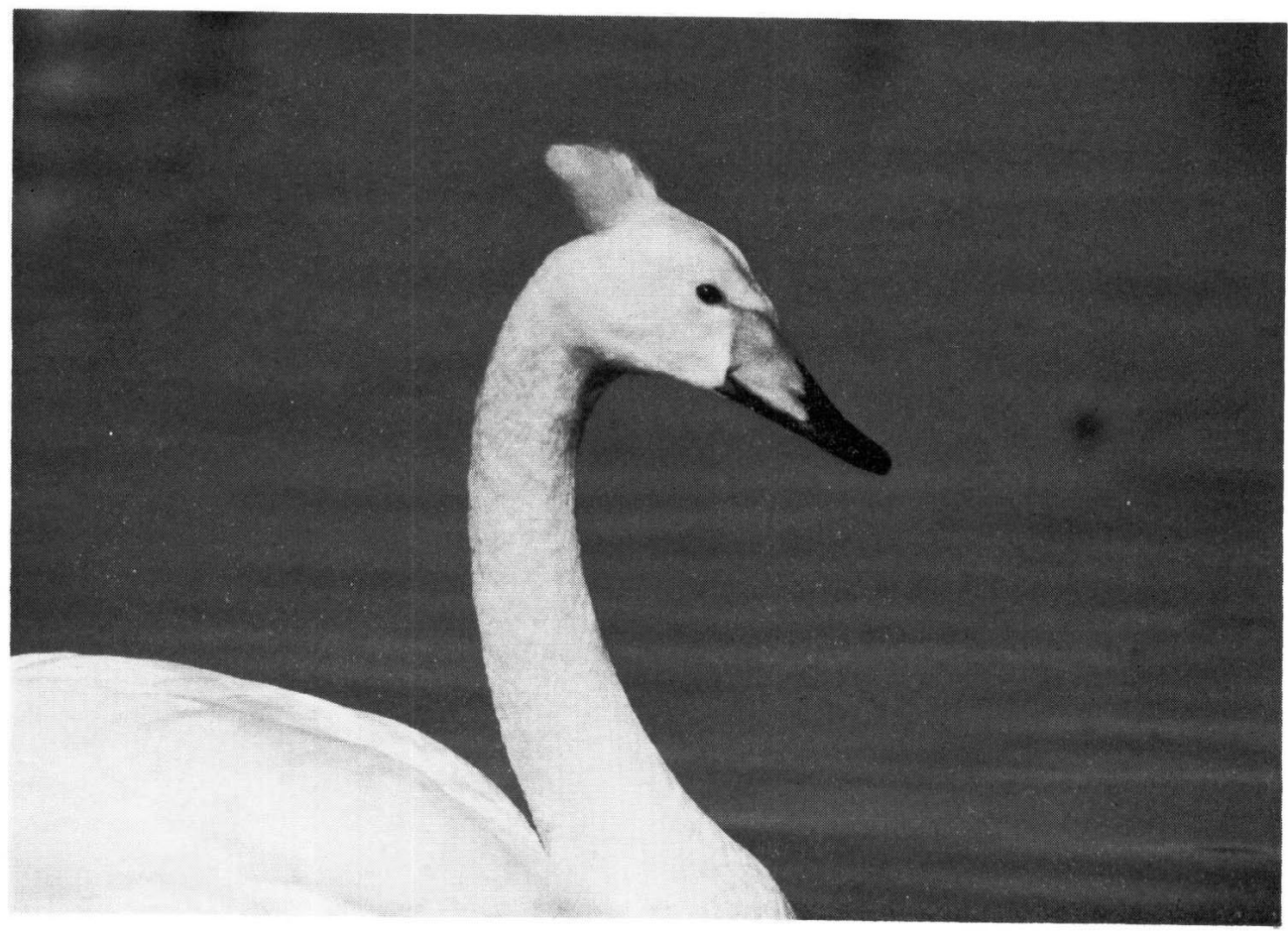



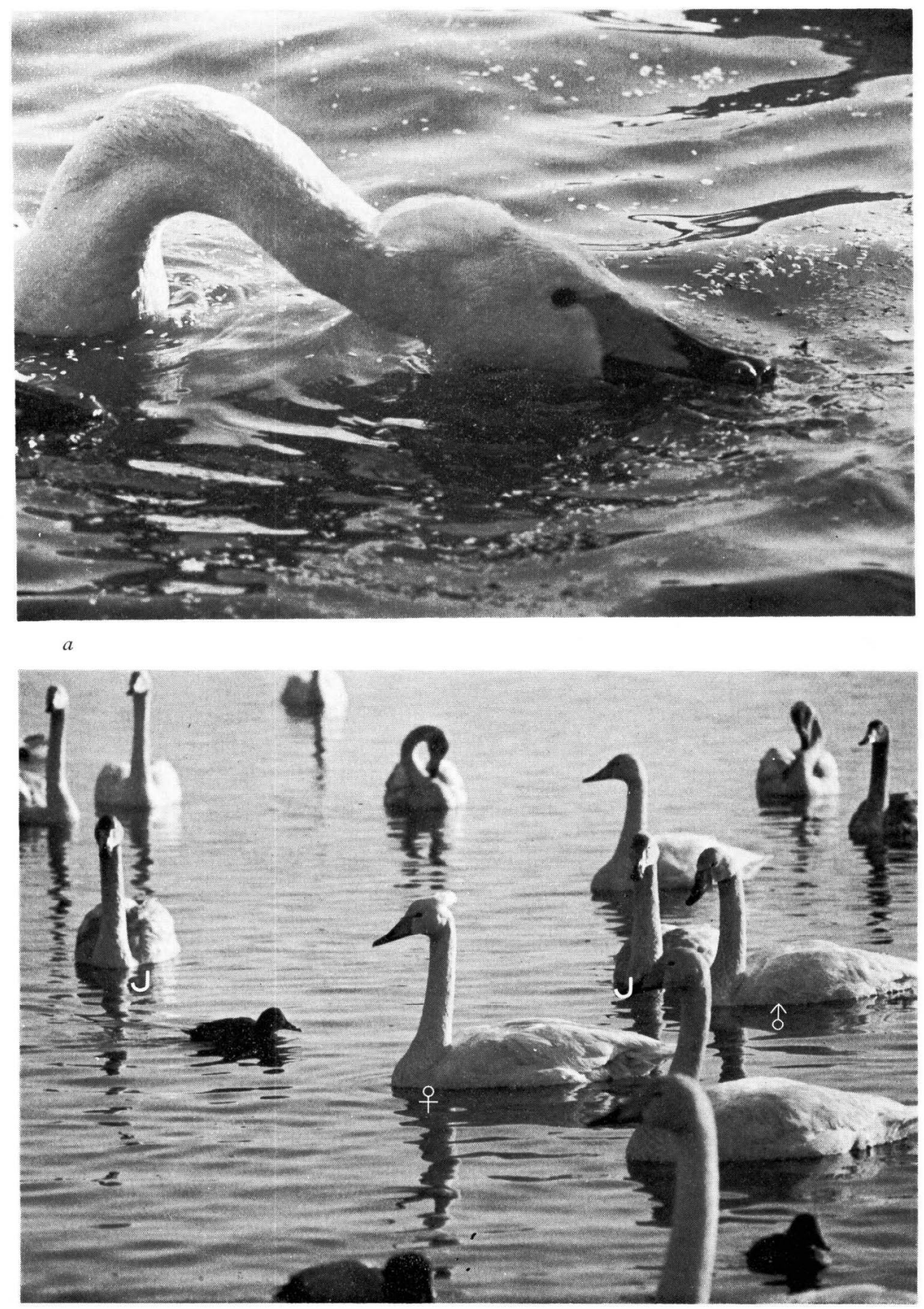